\title{
Respon tanaman anggrek (Dendrobium sp.) terhadap pemberian paklobutrazol dan jenis naungan yang berbeda
}

\author{
(Response of orchid (Dendrobium sp.) to the application of paclobutrazol and different shade \\ types)
}

\author{
S. N. Hidayah, Karno, dan F. Kusmiyati \\ Agroecotechnology, Faculty of Animal and Agricultural Science, Diponegoro University \\ Tembalang Campus, Semarang 50275 - Indonesia \\ Corresponding E-mail: sarinoor48@gmail.com
}

\begin{abstract}
ABSTRAK
Penelitian bertujuan untuk mengkaji jenis naungan yang sesuai dan sasaran pemberian paklobutrazol yang tepat untuk pertumbuhan serta pembungaan anggrek Dendrobium sp. Penelitian menggunakan Pooled Design dengan perlakuan naungan : N1 (naungan 30\%), N2 (naungan 50\%), N3 (naungan 70\%), serta cara pengaplikasian paklobutrazol : P0 (kontrol), P1 (disemprotkan pada akar), P2 (disemprotkan pada daun), P3 (disemprotkan pada akar dan daun), diulang sebanyak 3 kali. Parameter yang diamati meliputi tinggi tanaman, diameter batang, klorofil total, dan waktu inisiasi bunga anggrek. Data dianalisis ragam dan uji lanjut dengan BNT pada taraf $\alpha=5 \%$. Hasil penelitian menunjukkan bahwa naungan $50 \%$ berpengaruh pada tinggi tanaman $(26,97 \mathrm{~cm})$ dan diameter batang $(1,57 \mathrm{~cm})$, naungan $70 \%$ juga berpengaruh terhadap tinggi tanaman anggrek $(29,30 \mathrm{~cm})$ dan klorofil total $(0,55 \mathrm{mg} /$ g). Paklobutrazol tidak memiliki pengaruh terhadap tinggi tanaman dan diameter batang. Paklobutrazol hanya berpengaruh terhadap kandungan klorofil total. Interaksi antara perlakuan naungan $70 \%$ dan pemberian paklobutrazol pada daun, menunjukkan kadar klorofil tertingi sebesar $0,71 \mathrm{mg} / \mathrm{g}$. Faktor pemberian naungan dan paklobutrazol tidak mempengaruhi pembungaan anggrek, tapi inisiasi bunga mulai terlihat di beberapa tanaman. Waktu inisiasi bunga terjadi saat hari ke $71-126$ setelah perlakuan. Semua inisiasi bunga tidak dapat berkembang menjadi rangkaian bunga.

Kata kunci: anggrek, paklobutrazol, naungan, pertumbuhan, pembungaan.
\end{abstract}

\begin{abstract}
The research aimed to examine the appropriate shade types and target of paclobutrazol giving for growth and flowering of Dendrobium $s p$. The research used Pooled Design with shade treatment: N1 (30\% shade), N2 (50\% shade), N3 (70\% shade), treatment of paclobutrazol application: P0 (control), P1 (sprayed on roots), P2 (sprayed on leaf), P3 (sprayed on roots and leaf), replicated three times. Parameters measured were plant height, stem diameter, total chlorophyll, and the initiation time of orchid flowers. Data analyzed with anova and followed by LSD at $\alpha=5 \%$. The results showed that $50 \%$ shade affect plant height $(26.97 \mathrm{~cm})$ and stem diameter $(1.57 \mathrm{~cm})$, the $70 \%$ shade also affect plant height $(29.30$ $\mathrm{cm})$ and total chlorophyll $(0.55 \mathrm{mg} / \mathrm{g})$. Paclobutrazol has no effect on plant height and stem diameter. Paclobutrazol only affect the total chlorophyll content. The interaction between the shade treatment of $70 \%$ and the application of paclobutrazol in leaves, showed the highest total chlorophyll content of 0.71 $\mathrm{mg} / \mathrm{g}$. Shading and paclobutrazol factors do not affect the flowering of orchids, but the flower initiation begins to be seen in some plants. The initiation time of flower occurs at days 71 to 126 after treatment. All flowers initiation didn't develop into a flower arrangement.

Keyword: orchid, shade, paclobutrazol, growth, flowering
\end{abstract}




\section{PENDAHULUAN}

Anggrek Dendrobium sp. merupakan anggrek yang banyak digemari oleh masyarakat. Produksi komoditas anggrek tahun 2010 yaitu 14.050.445 tangkai, dan meningkat sebesar 10,24\% pada tahun 2011 menjadi 15.490.256 tangkai (BPS, 2011). Tahun 2013 produksi anggrek menurun sebanyak 15.456 .959 tangkai dibandingkan dengan tahun 2012 yang produksinya mencapai 20.727.891 tangkai (BPS, 2014). Permintaan pasar yang relatif tinggi dan terjadinya penurunan produksi, memicu adanya pembaharuan dalam teknologi budidaya tanaman anggrek khusunya masalah pembungaan.

Pertumbuhan dan pembungaan anggrek dipengaruhi oleh dua faktor, yaitu faktor internal dan eksternal. Faktor internal yang dapat mempengaruhi pertumbuhan dan perkembangan anggrek yaitu umur tanaman, kondisi fisiologis, dan kondisi hormonal. Pemberian paklobutrazol diharapkan mampu menghambat hormon pertumbuhan sehingga memicu munculnya bunga. Paklobutrazol termasuk senyawa inhibitor yang dapat menghambat kerja hormon giberelin sehingga mempengaruhi pertumbuhan tanaman (Rubiyanti, 2014). Kandungan giberelin yang tinggi akan menghambat pembungaaan, sehingga diperlukan paklobutrazol untuk menurunkan kandungan giberelin agar tanaman dapat menginduksi bunga (Budiyanto et al., 2010). Tanaman anggrek yang diberi senyawa paklobutrazol dapat berbunga pada hari ke 40 180 setelah perlakuan (Hasan et al., 2012).
Faktor eksternal yang mempengaruhi pembungaan adalah kondisi lingkungan dan kondisi media tanam. Pemberian naungan yang sesuai diharapkan mampu memberikan kondisi lingkungan yang ideal untuk pertumbuhan tanaman. sehingga naungan yang diperlukan sebesar $50-60 \%$ (Harahap, 2010). Tanaman anggrek yang tumbuh pada lingkungan yang tidak ternaungi akan menimbulkan bercak kecoklata pada daunnya. Daun anggrek yang kecoklatan seperti terbakar, disebabkan karena besarnya penyerapan sinar matahari oleh lapisan sel di bawah epidermis daun (Susanto et al., 2006). Naungan dapat mempengaruhi laju transpirasi. Cepatnya laju transpirasi dapat mengakibatkan jaringan kehilangan turgiditasnya sehingga tanaman menjadi layu (Suyitno, 2006).

Penelitian bertujuan untuk mengkaji jenis naungan yang sesuai dan sasaran pemeberian paklobutrazol yang tepat untuk pertumbuhan serta pembungaan anggrek Dendrobium sp.

\section{MATERI DAN METODE}

Penelitian telah dilaksanakan pada tanggal 24 Februari - 30 Juli 2017 di Screen House Perumahan Wahyu Utomo, Kecamatan Ngaliyan, Kabupaten Semarang, serta di Laboratorium Ekologi dan Produksi Tanaman, Laboratorium Fisiologi dan Pemuliaan Tanaman Fakultas Peternakan dan Pertanian, Universitas Diponegoro, Semarang.

\section{Materi}

Tabel 1. Rerata Tinggi Tanaman Anggrek Dendrobium sp.

\begin{tabular}{|c|c|c|c|c|}
\hline \multirow{2}{*}{$\begin{array}{c}\text { Aplikasi } \\
\text { Paklobutrazol }\end{array}$} & \multicolumn{3}{|c|}{ Tinggi Tanaman } & \multirow{2}{*}{ Rerata } \\
\hline & Naungan $30 \%$ & Naungan $50 \%$ & Naungan $70 \%$ & \\
\hline P0 & \multicolumn{3}{|c|}{ 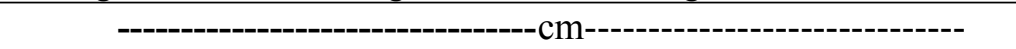 } & 27,62 \\
\hline $\mathrm{P} 1$ & 23,53 & 30,83 & 30,90 & 28,42 \\
\hline P2 & 25,30 & 26,17 & 24,67 & 25,38 \\
\hline P3 & 24,53 & 24,27 & 31,13 & 26,64 \\
\hline Rerata & $24,78^{\mathrm{b}}$ & $26,97^{\mathrm{ab}}$ & $29,30^{\mathrm{a}}$ & \\
\hline
\end{tabular}

- Superskrip berbeda pada baris rerata menunjukkan perbedaan nyata $(\mathrm{P}<0,05)$.

- P0 (kontrol), P1 (disemprotkan pada akar), P2 (disemprotkan pada daun), P3 (disemprotkan pada akar dan daun). 
Bahan yang digunakan dalam penelitian ini adalah bibit anggrek umur 8 bulan, arang kayu dan sabut kelapa sebagai media tanam, plastik untuk menutup akar saat aplikasi paklobutrazol ke daun, serta pupuk cair SOT dan D.I. Grow Merah. Paranet $30 \%$, 50\%, dan $70 \%$ sebagai media naungan. Plastik UV untuk melindungi tanaman anggrek dari sinar ultraviolet. Phefoc sebagai fungisida dan insektisida, serta paklobutrazol 250 ppm untuk merangsang pembungaan. Peralatan yang digunakan yaitu penggaris, jangka, Portable Leaf Area Meter, pot plastik, pipet, hand sprayer, pisau, gunting dan alat tulis.

\section{Metode}

Tabel 2. Rerata Diameter Batang Tanaman Anggrek Dendrobium sp.

\begin{tabular}{ccccc}
\hline \hline Aplikasi & \multicolumn{3}{c}{ Diameter Batang } & \multirow{2}{*}{ Rerata } \\
\cline { 2 - 4 } Paklobutrazol & Naungan 30\% & Naungan 50\% & Naungan 70\% & \\
\hline & ---97 & 1,53 & 1,20 & 1,23 \\
P0 & 0,97 & 1,60 & 1,27 & 1,38 \\
P1 & 1,27 & 1,47 & 1,07 & 1,17 \\
P2 & 0,97 & 1,67 & 1,30 & 1,37 \\
P3 & 1,13 & $1,57^{\mathrm{a}}$ & $1,21^{\mathrm{b}}$ \\
\hline Rerata & $1,08^{\mathrm{b}}$ & &
\end{tabular}

- Superskrip berbeda pada baris rerata menunjukkan perbedaan nyata $(\mathrm{P}<0,05)$.

- P0 (kontrol), P1 (disemprotkan pada akar), P2 (disemprotkan pada daun), P3 (disemprotkan pada akar dan daun).

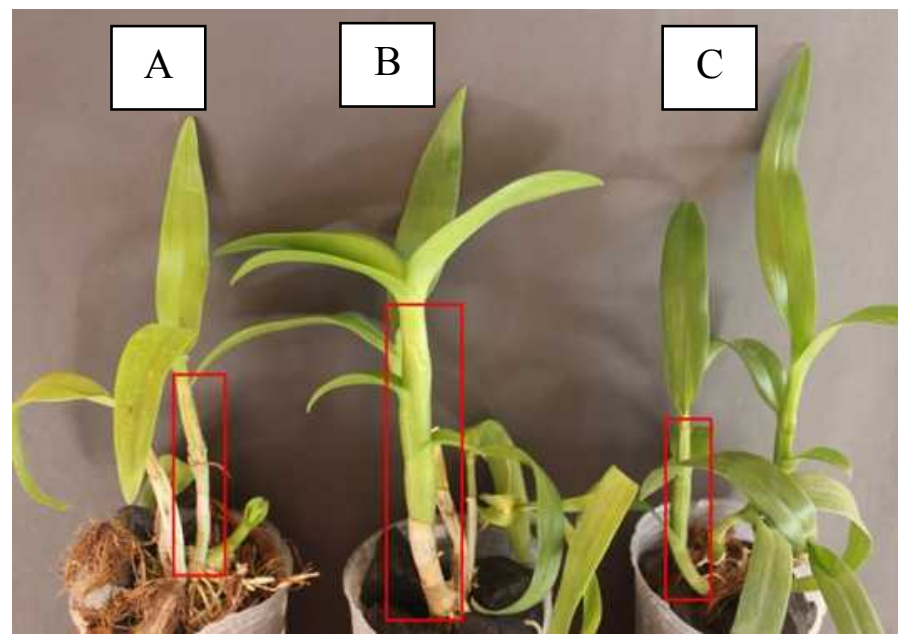

Ilustrasi 1. Sampel tanaman anggrek Dendrobium sp. pada naungan 30\% (A), naungan $50 \%(B)$, dan naungan $70 \%(C)$. 
dilakukan selama satu minggu sekali dengan total penyemprotan sebanyak 5 kali. Paklobutrazol disemprotkan pada akar (P1), daun (P2), serta pada daun dan akar (P3) sebanyak 20 kali semprotan. Tinggi tanaman diukur menggunakan penggaris, diameter batang diukur menggunakan jangka dan penggaris, klorofil total dianalisis menggunakan metode spektofotometri, dan waktu anggrek Dendrobium sp. tercantum di dalam Tabel 1 .

Hasil uji BNT menunjukkan bahwa tinggi tanaman pada perlakuan naungan $70 \%(\mathrm{~N} 3)$ tidak berbeda nyata dengan perlakuan naungan $50 \%$ $(\mathrm{N} 2)$, tetapi nyata lebih tinggi $(\mathrm{P}<0,05)$ jika dibandingkan dengan hasil pada perlakuan naungan 30\% (Tabel 1). Hal ini menunjukkan

Tabel 3. Rerata Klorofil Total Tanaman Anggrek Dendrobium sp.

\begin{tabular}{|c|c|c|c|c|}
\hline \multirow{2}{*}{$\begin{array}{c}\text { Aplikasi } \\
\text { Paklobutrazol }\end{array}$} & \multicolumn{3}{|c|}{ Klorofil Total } & \multirow{2}{*}{ Rerata } \\
\hline & Naungan $30 \%$ & Naungan $50 \%$ & Naungan $70 \%$ & \\
\hline P0 & $0,324^{\mathrm{e}}$ & $0,388^{\text {cde }}$ & $\begin{array}{l}\mathrm{g} \\
0,529^{\mathrm{b}}\end{array}$ & $0,414^{\mathrm{b}}$ \\
\hline P1 & $0,364^{\text {de }}$ & $0,337^{\mathrm{de}}$ & $0,470^{\mathrm{bc}}$ & $0,390^{\mathrm{b}}$ \\
\hline P2 & $0,387^{\text {cde }}$ & $0,397^{\text {cde }}$ & $0,711^{\mathrm{a}}$ & $0,498^{\mathrm{a}}$ \\
\hline P3 & $0,354^{\text {de }}$ & $0,422^{\text {cd }}$ & $0,474^{\mathrm{bc}}$ & $0,417^{\mathrm{b}}$ \\
\hline Rerata & $0,357^{b}$ & $0,386^{\mathrm{ab}}$ & $0,546^{\mathrm{a}}$ & \\
\hline
\end{tabular}

- Superskrip yang berbeda pada kolom dan baris rerata menunjukkan perbedaan yang nyata $(\mathrm{P}<0,05)$.

- Superskrip yang berbeda pada kolom interaksi menunjukkan perbedaan yang nyata $(\mathrm{P}<0,05)$.

- P0 (kontrol), P1 (disemprotkan pada akar), P2 (disemprotkan pada daun), P3 (disemprotkan pada akar dan daun).

inisiasi bunga diamati selama 2 hari sekali.

\section{Rancangan Percobaan dan Analisis Data}

Penelitian menggunakan rancangan Pooled Design, dengan perlakuan naungan : N1 (naungan $30 \%$ ), N2 (naungan 50\%), N3 (naungan 70\%), serta cara pengaplikasian paklobutrazol : P0 (kontrol), P1 (disemprotkan pada akar), P2 (disemprotkan pada daun), P3 (disemprotkan pada akar dan daun), diulang sebanyak 3 kali. Parameter yang diamati meliputi tinggi tanaman, diameter batang, klorofil total, dan waktu inisiasi bunga anggrek. Data dianalisis ragam dan uji lanjut dengan BNT pada taraf $\alpha=5 \%$.

\section{HASIL DAN PEMBAHASAN}

\section{Tinggi Tanaman}

Hasil analisis ragam menunjukkan bahwa tidak ada interaksi antara perlakuan jenis naungan dan aplikasi paklobutrazol terhadap tinggi tanaman. Hasil uji BNT perlakuan naungan dan aplikasi paklobutrazol terhadap tinggi tanaman bahwa naungan $50 \%$ dan $70 \%$ merupakan jenis naungan yang dapat mempercepat pertumbuhan tinggi tanaman. Tanaman yang berada di naungan $50 \%$ proses fotosintesisnya bekerja maksimal sehingga mengakibatkan penumpukan energi. Energi yang dihasilkan mempengaruhi proses pertumbuhan sel tanman sehingga berdampak pada tinggi tanaman. Pamungkas et al. (2009) menyatkan bahwa metabolisme cadangan nutrisi dari proses fotosintesis menghasilkan energi yang dapat mendorong pembelahan sel dan membentuk sel baru dalam jaringan. Pada naungan 70\% sinar yang masuk lebih sedikit dari jenis naungan yang lain. Hal ini menjadikan lingkungan tumbuh tanaman terlihat lebih gelap, sehingga dapat memacu proses etiolasi. Susanto et al. (2006) menyatakan bahwa etiolasi dapat terjadi jika tanaman hidup di lingkungan yang minim cahaya sehingga menyebabkan pemanjangan bagian tanaman.

Hasil uji BNT menunjukkan bahwa pemberian paklobutrazol di bagian tubuh tanaman yang berbeda, tidak berpengaruh nyata terhadap 

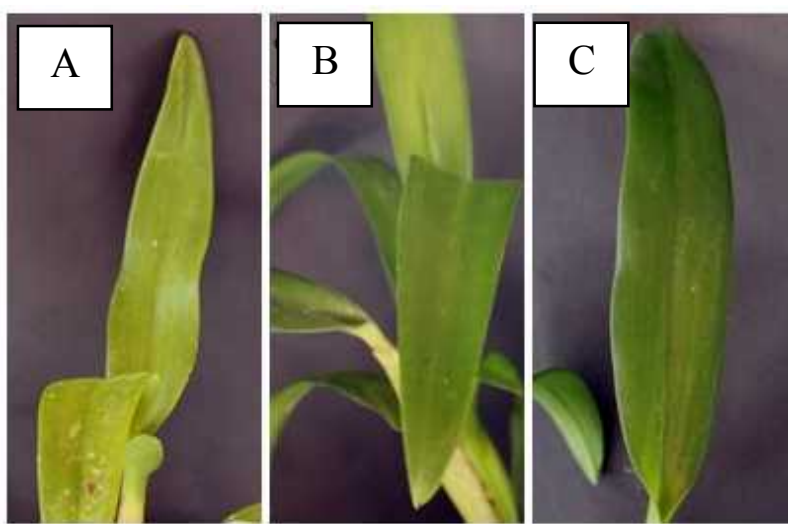

Ilustrasi 2. Perbedaan warna daun anggrek Dendrobium sp. pada naungan $30 \%(\mathrm{~A})$, naungan $50 \%(\mathrm{~B})$, dan naungan $70 \%(\mathrm{C})$.

pertumbuhan tinggi tanaman anggrek Dendrobium sp. Hal ini membuktikan bahwa fungsi paklobutrazol tidak bekerja secara maksimal sebagai senyawa yang dapat menghambat proses pemanjangan sel. Sedangkan Ningsih (2008) menyatakan bahwa paklobutrazol mengandung senyawa organik sintetik yang dapat menghambat pemanjangan sel pada meristem sub apikal. Faktor yang dapat mempengaruhi kerja paklobutrazol sebagai senyawa penghambat pertumbuhan adalah tersedianya unsur hara dan kemampuan tanaman dalam menyerap unsur hara tersebut. Tirta (2006) menyatakan bahwa kandungan unsur hara yang mencukupi terutama kandungan unsur nitrogen, dapat menyebabkan pertumbuhan vegetatif menjadi lebih baik.

\section{Diameter Batang}

Hasil analisis ragam menunjukkan bahwa tidak ada interaksi antara perlakuan jenis naungan dan cara aplikasi paklobutrazol terhadap diameter batang. Hasil uji BNT perlakuan naungan dan aplikasi paklobutrazol terhadap diameter batang tanaman anggrek Dendrobium sp. tercantum di dalam Tabel 2.

Hasil uji BNT menunjukkan bahwa perlakuan naungan $50 \% \quad(\mathrm{~N} 2)$ menghasilkan diameter batang $1,567 \mathrm{~cm}$ nyata lebih tinggi $(\mathrm{P}<0,05)$ dibanding perlakuan lainnya (Tabel 2). Hal ini menunjukkan bahwa naungan $50 \%$ merupakan jenis naungan yang sesuai untuk pertumbuhan diameter batang. Pada naungan $50 \%$ proses fotosintesis berlangsung secara maksimal. Cadangan makanan yang dihasilkan kemudian disimpan di batang, sehingga mempengaruhi diameter batang (Ilustrasi 1). Parnata (2007)

Tabel 4. Waktu Inisiasi Bunga.

\begin{tabular}{lc}
\hline \multicolumn{1}{c}{ Perlakuan } & Waktu Inisiasi \\
\hline Naungan 30\% + control & ----- hari setelah perlakuan ----- \\
Naungan 30\% + paklobutrazol ke akar (1) & 126 \\
Naungan 30\% + paklobutrazol ke akar (2) & 119 \\
Naungan 50\% + paklobutrazol ke akar (1) & 716 \\
Naungan 50\% + paklobutrazol ke akar (2) & 82 \\
Naungan 50\% + paklobutrazol ke akar (3) & 78 \\
Naungan 50\% + paklobutrazol ke akar dan daun (1) & 112 \\
Naungan 50\% + paklobutrazol ke akar dan daun (3) & 112 \\
\hline
\end{tabular}



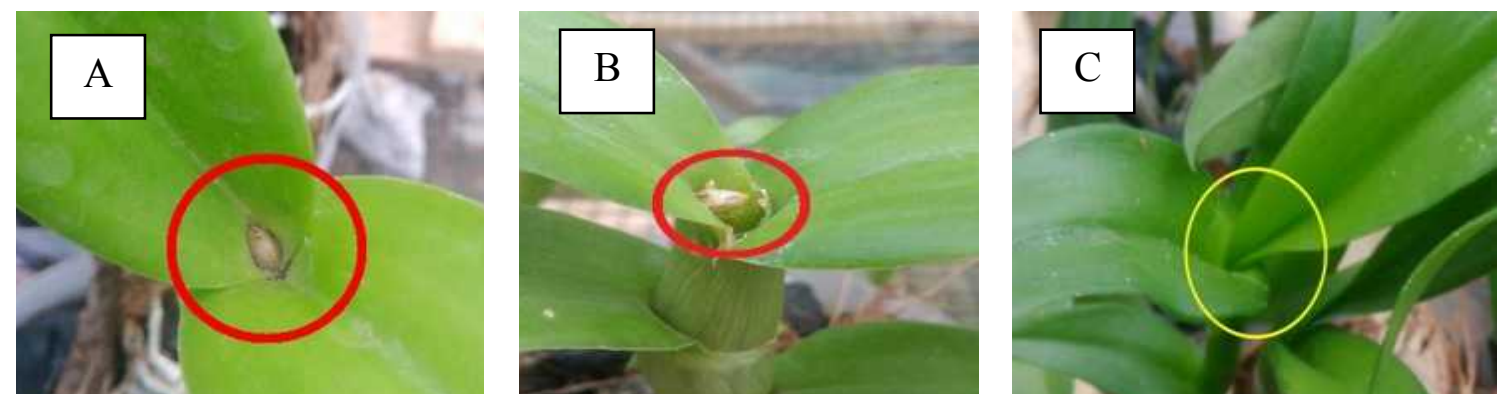

Ilustrasi 3. Inisiasi bunga pada perlakuan naungan 30\% dan kontrol (A), inisiasi bunga pada perlakuan naungan $50 \%$ dan pemberian paklobutrazol ke akar (B), contoh tanaman yang tidak berinisiasi (C).

menyatakan bahwa saat terjadi penumpukan hasil fotosintesis, tanaman anggrek akan cenderung menyimpan cadangan makanannya pada daerah batang. Sedangkan tanaman anggrek pada naungan 30\% menghasilkan diameter batang yang terkecil yaitu $1,083 \mathrm{~cm}$ (Tabel 2). Hal ini dapat terjadi karena laju transpirasi yang tinggi sehingga batang tanaman menjadi agak mengkerut. Sudaryonyo (2004) menyatakan bahwa intensitas matahari yang tinggi akan mempercepat transpirasi sehingga dapat menghambat proses pembelahan atau pembesaran sel.

Hasil uji BNT menunjukkan bahwa pemberian paklobutrazol di bagian tubuh tanaman yang berbeda, tidak berpengaruh nyata terhadap pertumbuhan diameter batang. Hal ini menunjukkan bahwa fungsi paklobutrazol tidak bekerja maksimal sebagai senyawa yang dapat meningkatkan diameter batang. Sedangkan Parnata (2007) menyatakan bahwa paklobutrazol dapat meningkatkan pembesaran diameter batang sejalan dengan pertumbuhan tinggi tanaman yang relatif pendek. Salah satu faktor yang dapat mempengaruhi pembesaran diameter batang adalah kemampuan tanaman menyerap unsur hara, jika kemampuan penyerapan unsur hara tinggi maka kinerja paklobutrazol kurang maksimal. Hasan et al. (2012) menyatakan bahwa kemampuan penyerapan unsur hara oleh tanaman dapat meningkatkan hasil fotosintesis sehingga berdampak pada penimbunan cadangan makanan di batang.

\section{Klorofil Total}

Hasil analisis ragam menunjukkan bahwa terdapat interaksi antara perlakuan jenis naungan dan aplikasi paklobutrazol terhadap kandungan klorofil total. Hasil uji BNT perlakuan naungan dan aplikasi paklobutrazol terhadap klorofil total tanaman anggrek Dendrobium sp. tercantum di dalam Tabel 3.

Hasil uji BNT menunjukkan bahwa interaksi antara perlakuan paklobutrazol dan naungan 30\% tidak memiliki pengaruh nyata. Hal ini menunjukkan bahwa paklobutrazol tidak bekerja secara maksimal di bawah naungan 30\%. Tanaman pada naungan $30 \%$ menerima paparan cahaya yang diterima lebih besar dari naungan lainnya. Paparan cahaya yang besar dapat merusak sel daun sehingga menghambat terbentuknya klorofil di dalamnya. Sumenda et al. (2011) menyatakan bahwa faktor -faktor yang mempengaruhi pembentukan klorofil dalam sel daun antara lain gen, cahaya, unsur $\mathrm{N}, \mathrm{Mg}$, dan Fe. Warna daun yang dihasilkan juga beberdabeda sesuai dengan jenis naungannya (Ilustrasi 2). Pamujiningtyas dan Susila (2016) menyatakan bahwa naungan dapat mempengaruhi kualitas warna daun, karena daun yang ternaungi memiliki kandungan klorofil lebih tinggi sehingga warna daun akan tampak lebih hijau.

Hasil uji BNT menunjukkan bahwa interaksi antara perlakuan paklobutrazol dan naungan 50\% tidak memiliki pengaruh nyata. Hal ini menunjukkan bahwa paklobutrazol tidak bekerja secara maksimal di bawah naungan 50\%. Faktor yang dapat mempengaruhi kinerja paklobutrazol yaitu kemampuan tanaman dalam merespon paklobutrazol tersebut. Menhennet (1979) menyatakan bahwa pengaruh retardan pada tanaman sangat bervariasi yang disebabkan karena adanya perbedaan kemampuan dalam 
mengabsorbsi dan translokasi senyawa kimia, adanya mekanisme penonaktifan dalam beberapa spesies, serta pola interaksi retardan dalam tanaman.

Hasil uji BNT menunjukkan bahwa interaksi antara perlakuan paklobutrazol dan naungan $70 \%$ memiliki pengaruh nyata. Kombinasi penyemprotan paklobutrazol pada daun dengan pemberian naungan $70 \%$ menghasilkan klorofil total sebanyak $0,711 \mathrm{mg} / \mathrm{g}$, nyata lebih tinggi $(\mathrm{P}<0,05)$ dibanding perlakuan lainnya (Tabel 3$)$. Hal ini sesuai dengan Wattimena (1988) yang menyatakan bahwa paklobutrazol dapat menyebabkan perubahan pada daun seperti pengecilan ukuran sel dan ruang interseluler, serta meningkatkan kandungan klorofil. Peningkatan kadar klorofil pada daun, juga dapat terjadi karena penyesuaian diri tanaman terhadap lingkungan hidup yang minim cahaya. Sirait (2008) menyatakan bahwa peningkatan klorofil pada tanaman yang ternaungi bertujuan untuk mengoptimalkan penangkapan cahaya yang tersedia.

\section{Inisiasi Bunga Anggrek}

Berdasarkan hasil penelitian, pemberian naungan dan paklobutrazol tidak mempengaruhi pembungaan pada anggrek Dendrobium sp. karena sebagian besar tanaman belum berbunga. Ditemukan juga beberapa tanaman yang mulai menunjukkan perubahan morfologis pada hari yang berbeda-beda (Tabel 4). Perubahan morfologis yang dialami yaitu munculnya kuncup reproduktif di ujung tanaman anggrek (inisiasi bunga) (Ilustrasi 3).

Inisiasi yang terbentuk tidak dapat berkembang menjadi rangkaian bunga. Hal ini dapat terjadi karena adanya dormansi tunas akibat aplikasi paklobutrazol yang dapat meningkatkan biosintesis asam absisat (ABA). Prawitasari et al. (2007) menyatakan bahwa pemberian paklobutrazol yang bertujuan untuk menginduksi bunga, harus diikuti dengan pemberian zat yang dapat memecah dormansi pasca aplikasi paklobutrazol. Wattimena (1987) menambahkan bahwa etilen merupakan zat pengatur tumbuh yang dapat mendorong pemecahan dormansi tunas, menghambat pertumbuhan batang, mendorong pembungaan, pembentukan buah dan umbi, inisiasi akar, penuaan, serta merangsang pengeluaran lateks. Perkembangan inisiasi bunga juga dapat dipengaruhi oleh waktu pemberian paklobutrazol. Pulungan et al. (2017) menyatakan bahwa terlambatnya pemberian paklobutrazol dapat mengakibatkan pembungaan terhambat karena paklobutrazol bekerja secara spesifik pada organ dan jenis tanaman.

\section{KESIMPULAN}

Berdasarkan penelitian dapat disimpulkan bahwa pemberian naungan $50 \%$ sesuai untuk pertumbuhan tinggi tanaman dan diameter batang. Pemberian naungan $70 \%$ sesuai untuk pertambahan tinggi tanaman dan dapat meningkatkan kandungan klorofil total. Paklobutrazol yang disemprotkan ke daun dapat meningkatkan klorofil total. Pemberian naungan dan penyemprotan paklobutrazol dapat merangsang inisiasi bunga, tetapi seluruh inisiasi tidak dapat membentuk rangkaian bunga.

\section{DAFTAR PUSTAKA}

Badan Pusat Statistik. 2011. Produksi Tanaman Hias Anggrek Tahun 2011. Badan Pusat Statistik, Jakarta.

Badan Pusat Statistik. 2014. Produksi Tanaman Florikultura Tahun 2009 - 2013. Badan Pusat Statistik, Jakarta.

Budiyanto, O. D. Hajoeningtijas, dan B. Nugroho. 2010. Pengaruh saat pemangkasan cabang dan pemberian paclobutrazol terhadap hasil mentimun (Curcumis sativus L.) Agritech, 12 (2) : $100-113$.

Harahap, F. 2010. Teknik praktis membuat anggrek selalu berbunga. Jurnal Pengabdian Masyarakat. 16 (61) : $41-50$.

Hasan, R. H., Sarwa, dan I. G. R. Sadimantara. 2012. Respon tanaman anggrek Dendrobium sp. terhadap pemberian paklobutrazol dan pupuk organik cair. Penelitian Agronomi. 1 (1) : $71-78$.

Menhennet, R. 1979. Recent Development in The Use of Plant Growth Retardants. Plant 
Growth Regulator Group, London.

Ningsih, R. 2008. Penyimpanan dengan pertumbuhan minimal dan regenerasi in vitro purwoceng (Pimpinella pruatjan Molk.). Institut Pertanian Bogor, Bogor. Tesis.

Pamujiningtyas, B. K. dan A. D. Susila. 2016. Pengaruh aplikasi naungan dan pupuk daun terhadap pertumbuhan dan produksi selada (Lactuca sativa Var. Minetto) dalam teknologi hidroponik sistem terapung. Institut Pertanian Bogor, Bogor. Skripsi.

Pamungkas, F.T., S. Darmanti, dan b. Raharjo. 2009. Pengaruh konsentrasi dan lama perendaman dalam supermatan kultur Bacillus sp. 2DUCC-BR-K1.3 terhadap pertumbuhan stek horizontal batang jarak pagar (Jatropha curcas L.). Jurnal Sains dan Matematika. 17 (3) : 131 - 140.

Parnata, A. S. 2007. Panduan Budidaya Perawatan Anggrek. Agro Media Pustaka, Jakarta.

Rubiyanti, N. 2014. Pengaruh konsentrasi paklobutrazol dan waktu aplikasi terhadap mawar batik (Rosa hybrid L.). Agriculture Science. 1 (4) : $48-53$.

Sirait, J. 2008. Luas daun, kandungan klorofil, dan laju pertumbuhan rumput pada naungan dan pemupukan. JITV. 13 (2) : 109 - 116.

Sumenda, L., H. L. Rampe, dan F. R. Mantiri. 2011. Analisis kandungan klorofil daun manga (Mangifera indica L.) pada tingkat perkembangan daun yang berbeda. Jurnal Bioslogos. 1 (1) : $20-24$

Sudaryono. 2004. Pengaruh naungan terhadap perubahan iklim mikro pada budidaya tanaman tembakau rakyat. Jurnal Teknologi Lingkungan. 5 (1) : $56-60$.

Susanto, A. D., D. Wideiastoety, Y. Koesmaryono. 2006. Respon anggrek Mokara Chark Kwan terhadap perbedaan intesitas cahaya. Jurnal Agromet Indonesia. 20 (1) : $52-58$.

Suyitno. 2006. Pertukaran Zat dan Proses Hilangnya Air. FMIPA Universitas Negeri Yogyakarta, Yogyakarta.

Tirta, I. G. 2006. Pengaruh beberapa jenis media tanam dan pupuk daun terhadap pertumbuhan vegetatif anggrek Jamrud (Dendrobium macrophyllum A. Rich.). Biodiversitas. 7 (1) : $81-84$.

Wattimena, G. A. 1987. Zat Pengatur Tumbuh Tanaman. Institut Pertanian Bogor, Bogor. 